\title{
Somatic Skill Transmission as Storytelling: The Role of Embodied Judgement in Taijutsu Practice
}

\author{
Katja Pettinen
}

In this article, I explore the nature of somatic skill and skilltransmission in the context of Taijutsu, a traditional Japanese martial art that has become increasingly popular among North Americans. I do so in order to argue that practitioners master advanced skills through an embodiment that is not singular and autonomous but instead profoundly reliant upon the bodies of others. Because this art is predominantly taught and studied through tactile bodily contact - practicing movement or kata in pairs rather than against opponents that are visualized-embodiment itself is directly positioned and shaped through interaction with other mindbodies. The nature of learning these movements is also culturally specific, and this specificity offers an especially complex way in which to reflect on intersubjective embodiment - and its import for judgement - as many North Americans travel to Japan to study and practice.

My exploration into what precisely constitutes an advanced skill in this martial art is based on long-term ethnographic work among practitioners of Taijutsu and, more specifically, is informed by ten years of sustained inquiry in which I have studied these skills together with other practitioners of the art, both in North America and Japan. My own changing embodiment over the years, in this way, provokes central insights into how the nature of learning Taijutsu movements is an intersubjective somatic process, centered upon shared bodily interactions. Based on ethnographic interviews and fieldwork, predominantly in North America, I describe the insights into somatic skill and skill acquisition at work within this non-competitive and relatively non-standardized martial art.

These skills exemplify an attentiveness to variation, variation in how the art is taught and variation in the execution of movements themselves. By foregrounding the cultural specificity of Taijutsu, I examine the dissonance between North American and Japanese-based assumptions about the nature of movement and skill acquisition. In contrast to the performance-based models upheld by many North Americans, Taijutsu makes use of a non-linear model of teaching. This 
model of movement focuses upon the feet. It also emphasizes the importance of learning to feel and perceive, rather than to execute movements automatically. This pedagogical practice can seem counterintuitive to a North American learner who expects an emphasis on rote repetition and presumed muscle memory; in contrast to Western expectations, Taijutsu teaching relies upon the cultivation of sensorial perception, itself a form of judgement that allows practitioners to master advanced skills.

North American students at times challenge the way in which teaching is approached in Japan. For example, when a foreigner visits Japan in order to study Taijutsu, this experience often disrupts the linear models of learning that most practitioners have at one point been taught the art through in North America: linear models which presume relatively stable basics onto which higher level of skills are thought to built on. I take these disruptions to be indexes of contrasting epistemologies about what skills and expertise are thought to be and specifically, the role that sensorial judgement plays in this learning.

Certain aspects of Taijutsu training can be seen as forming habits, habits that are as much about perceiving as they are about executing particular movements. While the body physically needs to be able to execute certain movements efficiently and fluently, a thoroughly internalized notion of a habit can only lead to a rigidity of movement patterns. Many semiotics thinkers such as Eduardo Kohn and Charles Sanders Peirce remind us that habits are an enabling feature of our being in the world. In order to learn, and in order to be alive, the organism has to be able to deal with a number of disruptions to its habitual ways of being in the world: "the breakdown of old habits and the rebuilding of new ones...constitutes our feeling of being alive and in the world" (Kohn 66). For Kohn therefore, such undoing of habits is not only a basic requirement of life itself but also a source of distinct sensorial pleasure among living organisms. Further, from this perspective, bodies cannot be regarded as objects but as "processes which extend into and are immersed in worlds" (Blackman 1). This essay makes the case for the significance of such sensorial pleasure, not only for the practitioners of Taijutsu but for embodied judgement more broadly.

\section{Tai-Jutsu: The Art of the Body}

In some thousand Taijutsu training halls or dojos across North America and the world, narratives about an eighty-year-old Japanese man called Masaaki Hatsumi circulate widely, narratives that center on the ways in which Hatsumi moves and the manner in which he uses his body. Hatsumi is the current soke or main teacher of several traditional Japanese martial art lineages that he calls collectively Bujinkan Taijutsu. This style 
combines nine martial lineages and has gained particular popularity outside of Japan.

Since turning seventy, Hatsumi no longer travels internationally to teach his art around the world, as he extensively did during previous decades. During the 1980s and 1990s, Hatsumi conducted numerous workshops, seminars, and demonstrations of his art in North America and Europe; at that point, Taijutsu was practically unknown in the west. As a result, the art gained a great deal of popularity globally and is now practiced actively throughout the west. Because Hatsumi is the sole originator and the main teacher of the art but no longer teaches it abroad, people from all over the world flock to the town of Noda, in Japan, located about $30 \mathrm{~km}$ north of Tokyo, where Hatsumi has a small dojo, always open for visiting students from abroad.

One of the main characteristics of Taijutsu as a martial art form is the comprehensiveness of its wide range of movements. Unlike a number of Japanese martial traditions which have come to specialize in a particular aspect of martial practice or budo - for example, Karate specializes in kicking and punching, whereas Judo specializes in the dynamics of throwing and body submission- Taijutsu maintains a holistic or a generalized approach to budo. As a non-competitive practice, centered upon self-defense rather than competing in tournaments, Taijutsu utilizes a variety of techniques, ranging from the use of different weapons (sword, long and short staff, spear, rope) to unarmed fighting methods (including strikes, kicks, joint and wrist manipulation, chokes, throws and body drops). Regardless of whether weapons are utilized or not, the skilled aspects of Taijutsu, literally translated as the "art of the body" (and, more specifically, the art of body movement), center on one's ability to judge distance, timing, and angle of movement.

Given the potentially dangerous nature of movements that aim specifically at self-defense, (rather than at competition or point sparring), practitioners of Taijutsu aim to have a high degree of awareness and sensitivity about what they are doing in order not to actually injure the person with whom they are training. A number of the body throws, for example, aim to tear ligaments rather than to score points. In the lexicon of some of the practitioners, therefore, one has to be able to "feel what is going on at all times" in order to train effectively and safely with people with varying body shapes and styles of embodiment.

In this sense, having a habit of doing movements in a particular manner regardless of the context would be to disregard the variation that is always present in the bodies of different individuals (i.e. height, weight, muscle density, neurology), and to disregard the manner in which they move and respond to one's own movements in a given particular moment. The inability to differentiate between such variations can lead to severe 
injuries in other people. One's knee might be torn, for example, by a person who executes a throw without the awareness that they are at the same time blocking the uke's knee with their own body. It is mainly for this reason, why a notion of automaticity, for example, cannot capture what being skilled means in any open-ended somatic context.

Consider for example how, when walking in the dark, we can feel our way through a familiar room without having to at any point say to ourselves, "This here is my favorite reading chair, this is my coffee table." Rather, we intimately know these objects and have a good feel for how they are positioned spatially in relation to each other, especially if we ourselves are moving across a familiar landscape like our own home. The reason for this is not because we repetitively walk from object to object, measuring and memorizing each relationship. Rather, the reason for our intimate familiarity is our continuous engagement with the space, which constitutes a central part of our selfhood and everyday living. If we had to draw an actual physically detailed representation of the room, however, we would likely be less skillful. In other words, familiarity and knowledge need not rely on distinctly internalized accounts of the external world. Rather, in order to effectively judge the spatial relations, including one's own body, one needs to engage with the space itself through movement.

One way to name this approach to conceptualizing skill in Taijutsu is to think about skill as the form of perception that Charles Sanders Peirce called "firstness," closely related to the Japanese notion of "becoming zero", or being nothing. . Peirce conceptualizes firstness as a possibility: not an idea but a possibility of an idea. He explains that "feeling is nothing but a quality, and a quality is not conscious: it is a mere possibility" (84). In precisely these terms, I suggest that advanced skill in Taijutsu is about the possibility of a movement's execution, more than the movement itself. Indeed, one of the expressions that the soke Hatsumi uses in his teaching of the advanced levels of the art is to advice the practitioners to "throw their technique away." This notion speaks to the Peircean concept of firstness. The advice aims to enable practitioners to move in the manner that is required by the parameters of the situation itself, rather than maintaining a predetermined set of actions regardless of circumstance.

\footnotetext{
${ }^{1}$ The notion of "becoming zero" or non-engagement is also commonly articulated in the context of Aikido practice wherein the founder of Aikido Morihei Ueshiba strongly advocated his tradition of martial practice as a path toward peace. In many Japanese arts, including Taijutsu, the principle of "becoming zero" is utilized in relation to advanced skill, for example, as a way of being able to deflate the attackers' energy by moving to the kinds of positions where he feels as if no good further attacks are possible. These kinds of conceptions are no doubt linked to the fact that many of the Japanese masters of traditional martial arts continue their practice well into an old age; these are not arts only for the young in their prime physique.
} 
Further, some situations require the absence of an action, rather than any direct action itself. In other words, one way to achieve a fluency of movement is to leave out non-necessary patterns of movement that might for example, signal to the opponent what is about to happen.

Instead of forming context-free habituated patterns of movement, an advanced Taijutsu practitioner must be able to continuously "uncoil" or undo habituated movements. In order to reach the kind of perceptive mechanism that I argue constitutes skill in Taijutsu, a practitioner must be able to shift focus from habits of doing-which in and of themselves emerge in everyone's movements - toward habits of embodied judgement. It is this habitual engagement with the heightened perceptive system that allows a practitioner to continuously challenge movement patterns that have become too rigid in the course of training. It is in this sense that I suggest advanced skill is about firstness in Peircean terms: about a capacity without any expectation, or desire in more Buddhist terms, for particular execution of a pre-determined movement pattern. The skill then is about the capacity to return back toward the realm of firstness, toward the capacity to judge without a commitment for further action.

Consequently, skill can be re-conceptualized as enacting perception through various overlapping sensory systems: through movement, hearing, touch, balance, resistance, vision. Moreover, these acts of perception must become continuous with body movement itself: to move is to perceive, to perceive is to move, together these modes of existence constituting a form of understanding and intelligence in their own right.

\section{Catching a Feeling}

In his ethnographic reflections on teaching, Tim Ingold argues that many prevailing models of knowledge, based on what he names the "genealogical modes of transmission," assume that the expert-whether a poet, potter, or a weaver-has gone through a process of learning where an ever increasing number of representations of the core skills become packed inside the expert's head ("Stories Against"). Such models assume that skills or knowledge are something that can be stored, perhaps somewhere in the brain matter of an individual. This closely echoes the assumptions about the nature of cognition that became popular during the first wave of cognitive science, following the emergence of computerized technologies in the 1970 s and 1980 s. $^{2}$ In these frameworks, the nature of

\footnotetext{
${ }^{2}$ For overviews of the development of cognitive science that examine its import for how we think about and engage with somatic practices, see Noë and Thompson.
} 
human cognition, and consequently any human skill and capacity at large, was reduced to a set of "programs" that the brain matter presumably houses in its synaptic connections. A common articulation of this is the phrase, "neurons that fire together, wire together," an idiom popularized by neurologist Gerald Edelman.

Rather than regarding skill or expertise as something maintained inside the brain, as for example a set of internalized representations of the external world, Ingold suggests that a more semiotically accurate way to conceptualize the nature of knowledge that is held by an expert knower is to posit that, compared with a novice, there is a "greater sensitivity to cues in the environment and a greater capacity to respond to these cues with judgement and precision" ("Stories Against" 203). Ingold's insights lead us to consider the ontological aspects of bodily skills. On this view, skills come into being through an elevated ability to read and respond to signs (i.e. proprioceptive, kinesthetic and tactile) - in other words, by cultivating one's capacity to judge and to differentiate - and not through an increased file storage or automation.

Expertise, then, takes place through heightened awareness and sensorial acuity, rather than through a neurological condition that is located inside one's crania. Translating this understanding of expertise to the context of Taijutsu practice, skill refers to the capacity to recognize one's own bodily potentials, as well as to the awareness about how the somatic self is positioned within a particular context or an environment. ${ }^{3}$ Ingold argues that such increased sensitivity allows skilled persons to share their knowledge, not through what in social theory has been ubiquitously named as "transmission"-namely, the assumptions about sharing knowledge based on a genealogical model- but through storytelling, storytelling that allows learners to grow into these modes of sensitivity. ${ }^{4}$

We find this kind of embodied storytelling at work within the teaching and learning of Taijutsu. Such storytelling ripples out from Japan to North America, in part through North American practitioners who travel frequently to Japan, and also through numerous books, videos, online discussions and other cultural artifacts that travel with these practitioners. Of course, as is the case with all forms of storytelling, this is not a medium of linear transmission.

\footnotetext{
${ }^{3}$ For a more detailed examination of this point, see Pettinen.

${ }^{4}$ A similar, earlier critique of the transmission model is found in Paolo Freire's work; Freire names such internally based accounts of knowledge and their presumed linear modes of transmission to others as the "banking model of education."
} 
A common expression (in English) that advanced practitioners use when teaching Taijutsu techniques is "catching the feeling." To catch a feeling of a technique seems to on some level supersede the assumption that one can learn techniques simply by repeating them enough or also by simply observing the techniques visually. While some amount of repetition or rather, continued exposure, is considered necessary in order to reach a basic level of fluency for certain movements, these movements are rarely done exactly in the same way. Rather, the emphasis in learning and teaching is on a holistic approach to bodily skills and on ability for context dependent variation.

In addition, the expression "to catch a feeling" is about foregrounding awareness and sensoriality: to always being able to adapt to any changes in the setting, including one's own body, this aspect directly challenges the notion of "technique" in and of itself. While some practitioners, at least in North America, teach with a more set curriculum, having a set of techniques or movements that a student needs to know as a basis for a certain belt rank for example, Hatsumi consistently challenges these modes of learning. He often tells people to "throw away their technique" in order to allow the art itself to come through. His numerous books on Taijutsu, translated into several languages, also challenge linearity: techniques are written down in manner where sometimes left and right executions of a movement are switched; pictures of these techniques might be in a mixed order; and some of the pictures are printed as mirror images.

By challenging linearity, and in essence, essentialism, or the notion that given set of movement patterns themselves ("techniques") are the end goals of somatic learning, Hatsumi evokes in his teaching a somatic practice that is transmitted through bodily storytelling, carefully crafted through sets of movements all building on each other. But in the course of learning, practitioners are not understood as becoming "installed" with an ever-increasing set of skills. Rather the longer-term goal of Taijutsu practice is at times described as "becoming zero" or empty, ceasing the need to do anything at all. This way of articulating the longer term goals of bodily skills are distinctly different from what any performance based linear models of learning foreground. In the prevailing Western accounts of bodily capacity, skills are generally thought of as particular capacities for action, such accounts also being distinctly gendered and linked with masculinity (Adams 76). ${ }^{5}$

\footnotetext{
${ }^{5}$ While martial arts practices are gendered in many ways, the categories through which such gendering occurs alter when crossing cultural boundaries. For example, unlike in western contexts where direct action is seen as a sign of the masculine (and, conversely, holding back or not engaging further might be read as "effeminate"), such reading does not hold in the context of Japanese martial arts. See Paradis.
} 
I meet up with a Taijutsu friend to do some training in her apartment. I've known Diane for several years now, and we have trained together in North America, as well as in Japan during our overlapping trip there two years ago. During that trip, Diane severely injured her knee and had to have surgery and take a year off from training. At this point, the last time that I trained with Diane was in Japan before her injury. Diane's recovery has been excellent, and as soon as we begin to work on some of the techniques I can sense her strength. The quality of the strength is not so much in terms of any absolute muscle mass; after all, she weighs around 130lbs maximum and is a good one-inch shorter than I am at 5'10 $(174 \mathrm{~cm})$. Rather, the quality of the strength that I am sensing is composed of the nuanced positioning of her movement, for example of the kind of placement of the feet that she utilizes. Whenever I deliver a strike toward Diane, she is able to move at the pace that mirrors my movement and angle her position in relation to my body in such a way where I have no further immediate attacks available, and my overall balance is compromised, although so subtly that I only notice this fact after reflecting on it later on through writing ethnographic fieldnotes.

One's capacity to judge different aspects of embodiment is constantly being cultivated in these interactions. Whether one is actively doing the techniques (tori) or receiving them (uke) through one's own mindbody, through practicing with others, one is learning to consciously notice what is going on with one's own body in relation to another body's actions upon it. Diane's skills, in other words, involve noticing the distance, timing and angle of my movements, at the same time that she enacts her own.

\section{The Grammar of the Feet}

Two months before this training session, I had met up with Diane when she had just returned from another training trip to Japan. We met for coffee and to conduct a semi-structured interview about her trip and her current understanding of the principles of the art, which at this point was based on seventeen years of training. Since she freshly back from Japan, Diane demonstrated the heightened enthusiasm about training and the art that most practitioners carry back with them from these trips (which on average last from ten days to few months; some Westerners end up moving to Japan all together in order to train very regularly).

During our conversation, Diane articulated the pleasure and excitement that one gains by training in Japan. In this context, she joined the highly global community of practitioners who gather to train in the art. 
Such a sense of community is heightened because, while there are many places to study the art, both in Japan and across the globe, Hatsumi has a personal dojo. Referred to as the hombu, or the "center" dojo for the art, Hatsumi has taught in one single location in Noda, Japan since the 1970s. As a result, many practitioners have trained in this one geographic point over the course of decades, always returning to the small town, $30 \mathrm{~km}$ north of Tokyo, during their trips to the country.

Diane explains that visiting Japan is in a sense very "addictive"she keeps wanting to go back again after each visit and has entertained the thought of moving to Japan, a plan that is currently on hold due to the pragmatic difficulties of being able to secure a permanent job in the country. She sums up her feelings about going to Japan for training: "It's like being on crack!" She laughs and continues:

I don't really know how to explain it, but the training is incredibly good. Being in the same room [at the hombu dojo] with fifty or more people, all of us training, moving together. It's kinda like moving meditation. That's the closest I've come to the experience elsewhere, I think. In some yoga classes you can get into this connectedness where everyone's movements are in sync, their breathing is in sync, and so that's a little bit similar.

Although she found training in Japan overall to be a meaningful, satisfying, and pleasurable experience, during her recent trip, Diane had several goals which she felt were not quite met. She explained:

I feel like we need more direct applications in our training. In the art we do a lot of sword work [as part of the Japanese tradition]. And I mean, how often is someone gonna attack you with a sword, in the society that we actually live in! [laughs] That's just not going to happen, you know. And yeah, I know that the idea is that there's something that will "transfer" from the techniques, that [from sword training] then you know how to defend yourself if being attacked by a baseball bat or something like that. But my point is why don't we just train more directly with that focus, with the kinds of attack scenarios that actually happen in real life? Just go directly into that focus instead hoping that something will "transfer" from these traditional techniques. People keep talking about Taijutsu as a "living art," but how living is it when we keep training with these traditional swords?

The first quotation from Diane reflects the pleasure and the sociality that many practitioners experience in the practice of this art. A different form of pleasure seems to be articulated in the second quotation, one that emerges in a certain tension with the notions about skill and capacity that Diane is expressing. 
The tension here has to do with contrasting conceptions of somatic learning. In other words, it has to do with epistemology and also about the ways in which epistemologies intersect with culture-with the kinds of conceptions that are readily available, for example linguistically, in relation to the overall question: what does it mean to be able to do things with and through one's own body? And in the case of Taijutsu, what does it mean to move in ways that attend to the unpredictable, open-ended, and variable ways in which other bodies move, movements that pose a challenge to one's own bodily balance and well-being?

From their trips to Japan, what many practitioners bring back to North America is a newly positioned perspective toward their training and teaching of the art. Here's how Diane put it back in May:

The first time I went to Japan, I thought oh no, all of our basics are totally wrong! [Our main American teacher] had this super linear system that he used, there was basically only one way of doing everything. And that was not how they we're doing these movements in Japan. And then I went back [to Japan] and it was different again!

The performance-based models of movement that proliferate in many learning contexts of North America (as well as in some areas of Japan as well) tend to highlight linearity, making the assumption, for example, that there are central starting points that the learner is first introduced to and that such "basics" then allow the learner to progress on this path of learning. An especially commonplace notion among North Americans is to view somatic skill as being founded upon repetition. In this framework of skill acquisition, a path to advanced skill lies in repeating certain movements themselves, or their parts as "drills," to such a degree that the person acquires complete automaticity in their ability to execute them, habitually and "without any thought."6 Expressions such as "muscle memory," motor skill and second nature, are frequently evoked in these frameworks. The overall etymology of automaticity more generally is complex and beyond the scope of the current essay. What can be briefly noted here is the manner in which such conceptualization stems from broader conceptions of materiality, nature, the "animal," and consequently the body, all being composed of entities that are driven by mechanical, developmental trajectories. ${ }^{7}$ Generally, such mechanical conceptions of nature and the body make use of Cartesian metaphysical assumptions: namely, that the "mind" and the "body" are distinctly separate realms, and

\footnotetext{
${ }^{6}$ For a paradigmatic example of skill acquisition that sets up such assumptions, see Fits and Puesner.

${ }^{7}$ For helpful elaboration of this point, see Gibson, Salthe, and Thompson.
} 
that the body is lower in value. In relation to somatic engagements, what follows is that the body is seen as an entity that can be trained to perform certain actions on command, without any presumed involvement of "thought" or "cognition."

In terms of movement learning, what the performance-based, accumulative models of movement foreground (what Ingold refers to as genealogical models of knowledge, premised upon linear transmission) is a particular conception of skill and particular assumptions about how to achieve such higher-level capacities of skill. This is where the teaching methods and the conceptions of skill at work within Hatsumi's tradition of Taijutsu model a strikingly different paradigm of skill and skillacquisition. Rather than emphasizing external judgement or passive seeing, this paradigm asks practitioners to utilize their own internal bodily knowledge ("feeling") as a means of judging, and hence of understanding, what is taking place in the course of an embodied interaction.

In terms of how the skill is taught, as Diane and anyone else who has trained the art in Japan over the previous decades have witnessed, most components of the art, including those movements that are considered the "basics," are offered in variable forms depending on the year and depending on the teacher (Hatsumi or one of his senior students in Japan who have studied with him for several decades). In part, this variation comes from the fact that differing individuals will interpret their learning of the art through varying body styles: some advanced teachers of the art are very small and slightly built, while others are heavily muscular and tall. As a result, the manner in which these individuals take up the principles of the art is in part dependent on their bodily styles and personalities. On the other hand, any one teacher will vary his or her teaching of the art from year to year, in part as a result of their own continued learning of the art.

Following Ingold's notion about how skilled practices are taught through storytelling rather than patterned repetition, we can recognize that all narration occurs through culturally specific ways. In the context of somatic practices such as Taijutsu, how movement itself is conceptualized is central to how it can be learned or passed on to others through these bodily modes of storytelling. What is striking in the case of Taijutsu practice is the manner in which this style and its principles of learning and teaching is exported to the cultural context of North America from Japan.

It is worth noting that the classic Western sports that align most closely with Japanese martial arts-such as boxing and fencing-tend to place strong emphasis upon the upper body. We find this bias also at work in a number of evolutionary accounts that rely upon a culturally stratified taxonomy of the body. Similarly, such storytelling about the human past, albeit in the scientific voice of evolutionary research, tends to emphasize 
the role of the hands in tool making, and later the head and the brain in relation to (presumed) decision making. Especially noteworthy in the context of my ethnographic analysis of Taijutsu, what most Western accounts of the body tend to leave out of more explicit focus are the feet. ${ }^{8}$

In contrast to such top-centered conceptions of the body, Taijutsu, as a Japanese art, emphasizes the feet as the foundation for all consequent movement patterns. Expressions such as "move your feet" or "use small feet"-meaning always take small steps, thus allowing one's movement to change directions at any point - can be heard frequently in the training spaces, as both students and teachers struggle to reach a fluidity of movement that the style is centered on. Many witness such fluidity, for example, in the movements of Masaaki Hatsumi and many of his senior students during their trips to Japan.

In contrast to many martial arts that are currently prevalent in North America, and especially in contrast with the manner in which they are taught, Taijutsu practice centers on a relatively non-unified approach to skill transmission. Instead of having a set of techniques or particular movements that the students learn in a strictly defined order or in light of a systematized curriculum, the teaching and learning of Taijutsu occurs in a variably and open-ended manner. In terms of its development, the art has not gone through an organizational process of institutionalization, as many other martial arts have, in part because, at this point in time, its founder, Masaaki Hatsumi, regards the tradition as something that should keep developing and changing from decade to decade. Consequently, when North Americans visit Japan to study the art, they often encounter a range of different strategies and focus points, even in relation to those techniques that are generally considered as fundamentals of the art.

However, what emerges as a one unified pattern across all of the variation of how given techniques are performed and utilized is the manner in which the use of the feet guides any consequent movement patterns. Through slight nuances in the placement of their feet, in relation to the other person's body and in relation to one's own balance structure, advanced practitioners are able to maneuver the opponent's body through throws, arm locks, and other means of bodily submission. North American practitioners themselves sometimes name this as the principle of "distance, timing, and angle." What is fundamental to the successful execution of a technique is when, where, and how it is executed, not simply the performance of the technique itself. In the course of such nuancing of the feet, what is actively utilized, along with any execution of a technique

\footnotetext{
${ }^{8}$ For critical reflections on these biases on evolutionary accounts, see Ingold and Verkunst.
} 
itself, is the sensorial awareness and acuity of how far to step, when, and in what kind of angle.

Japanese theatre theorist Tadashi Suzuki locates a similar theme in modern theatre training, pointing to the importance of feet in the broader context of Japanese culture. He criticizes modern Western theatre for its dependence on technological aides in production and argues that theatre training needs to be able to first provide actors a "grammar of the feet." The practice of Taijutsu seems to exemplify what Suzuki calls the grammar of the feet, a grammar that is structured through the senses and perception, rather than through the execution of particular techniques in and of themselves. The grammar of the feet consists of being able to provide a solid infrastructure for the possible execution of further movements, such as Diane's ability to lock my shoulder or to thrown my body once my balance had been slightly altered.

As explained above, Taijutsu does not aim to cultivate somatic skill in the context of competition. This is a significant point because competitive approaches to martial arts necessarily pre-define particular boundaries for the central patterns of movement (points are awarded in relation to pre-defined movements). In Taijutsu, the stated goal of training is to be able to defend one's self against people: people who might be significantly larger, stronger or faster than oneself, and who will not necessarily be guided by any rules about agreed upon movements. In other words, the overall focus is upon self-defense and preservation, regardless of the nature of the danger posed to the self. Perhaps because this form of capacity building is taken to be the central axis through which the mindbody, rather than "the body" as an object is cultivated, there is relatively little standardization in the movements or techniques that the art centers on. ${ }^{9}$ It is this particular aspect of Taijutsu-namely, its nonstandardization - that leads toward the possibility of naming the nature of the second embodied pleasure that it affords.

I suggest that this embodied pleasure is directly linked to the nature of strength that I described in the earlier section when describing a training session with Diane: the capacity that Diane demonstrated in immobilizing my strikes, strikes that I enacted in a variable manner. Despite this variation, one of the central patterns of Diane's movement was a capacity to move to positions in which her balance was better established in relation to my own; my balance, in turn, was compromised. In the terms of Taijutsu, from the perspective of the tori, the key is to effect these

\footnotetext{
${ }^{9}$ For noteworthy studies that exemplify this kind of attentiveness to the mindbody and that demonstrate the importance of resisting formulations of the body-as-object, see Hayles, Merrell, and Kuriyama.
} 
movements so subtly that the uke does not immediately notice what is occurring. As my reflection evinces, Diane's expertise in enacting such subtlety of movement was manifested in my own lack of awareness, in that present moment, of how Diane's movements were shifting my own.

In this reflection, I am not suggesting that pleasure emerges directly from one's capacity to execute these movements so effectively, or, indeed, to do anything directly. My account, in other words, is not a functional one. Instead, in terms of the ontology of skill in this kind of highly open-ended context, the composition of advanced skill is grounded upon one's perceptive and sensorial capacities: the ability of Diane to perceive not only what I was doing when delivering an attack (i.e. how fast I was moving) but what was happening to my mindbody in relation to her own movement when she was responding to my strikes. If Diane's movement to immobilize my balance was so obvious that I would notice it, then I would naturally respond to this kinesthetic challenge and alter my bodily posture. If, on the other hand, my perceptive capacities were not directly alerted, I would be more likely to remain in a compromised posture, from where it would be easier for Diane to further immobilize my body through a throw or a joint lock.

Based on this account of advanced Taijutsu practice, we can recognize how skill in this context includes one's capacity to judge and assess the kinesthetic interaction between the bodies; it is not sufficient to regard skill solely in terms of a set of movements or "techniques." In other words, somatic skill and capacity seem to lie at the intersection of one's own bodily knowledge - comprised of doing and perceiving - and one's knowledge of (and ability to notice) how an other person's mindbody has been impacted through one's own movement. What seems especially noteworthy here is that the nature of judgement exemplified by such skill involves both internal and external sensoriality; such embodied judgement contrasts with the exclusive emphasis on "externally" oriented senses that we often find in western philosophy and social theory. ${ }^{10}$

This account of embodied judgement has ontological implications for how we understand the relational context in which judgement takes place. Being able to judge - in other words, being able to make assessments about the particular details of how one exists within given moments of time-space continuum - is a form of sensorial awakening. ${ }^{11}$ In

\footnotetext{
${ }^{10}$ For analyses of the limitations of frameworks that privilege "externally" oriented senses, see Geurts, Howes and Classen, and Korsmeyer. Especially relevant for discussions of embodied judgement, such analyses invite skepticism about the ways in "externally" oriented senses are, in and of themselves, enumerated and delimited.

${ }^{11}$ See Mullis and Noë for detailed and engaging explorations of the broader ontological implications of this point, especially in terms of how living organisms at large experience such sensorial awakening as a form of pleasure.
} 
order to notice sensorial details, including for example the details about a kinesthetic interaction between two bodies, one has to be able to be present within such a world, rather than the world, or some external reality that presumably exists "out there," somehow separate from one's own embodiment. As Katherine N. Hayles puts it, in contrast to any distinct differentiation between organism and environment, "the world we know [as living organisms] is an active and dynamic construction that emerges from our interaction with the flux" (67).

An anecdote by semiotician Eduardo Kohn exemplifies the significance of this kind of sensorial awakening. Reflecting on his own experience, Kohn explains how bringing his attention toward another living organism, like a bird in its natural environment, allowed him to break out of the feeling of panic brought on by spiraling and disembodied thoughts about the possibilities of future events. By bringing his attentive focus to the living bird, Kohn made a return to the indexical and iconic world of movement and sensoriality. In his own words, Kohn explains that the shift away from the symbolic world of abstract thought to the world of movement "brought me back to my senses and the process regrounded me in a world beyond myself" (Kohn 57). It is precisely such anchoring in the present through heightened sensoriality both within and across other bodies that affords the embodied pleasure of Taijutsu practice.

\section{Conclusion}

In this essay, I highlight the ways in which the notion of skill in an ethnographically grounded analysis of Taijutsu practice cannot be reduced to a brain region, particularly in terms of isolate motor skills or "muscle memory." Instead, an ontological conceptualization of skill, in terms of individual practitioners, needs to consider the importance of sensorial systems and the processes of perception in general as the foundation from which any execution of a physical task can flow. To regard skill transmission as a form of story telling, a narrative process, rather than a banking transaction wherein something is directly passed on, is to recognize that the process of teaching is centered upon proper judgement as much it is centered upon the "how to" of given movement execution.

On a broader systems level, we can recognize that the location of skill in somatic practices cannot be reduced to a brain structure or region or even to a person. As Merlin Donald argues, referring to human capacities for thought and language at large, we need to consider the structures of our society as part of these cognitive capacities. Closely echoing the basic ideas of embodied cognition framework, Donald argues 
that human skilled action must be conceptualized in relation to the broader distributed symbolic systems that enable individuals to execute given tasks, one central technology being language itself. ${ }^{12}$ Consequently, one needs to be able to materially locate the concept of Taijutsu skill in the centuries-long martial tradition itself, as well as within the ecology of relations where these practices historically emerged, not only in individual actors. At the same time, Taijutsu is an intensive long-term cultivation of an individual's body, mind, and the embedded neurological system. ${ }^{13}$

On this level, I suggest that advanced skill is centered upon one's ability to perceive small changes within one's own body, in the other person's body, as well as in the relationships between these two energetic, material and psychological systems. These perceptive and sensorial capacities are centered on the proprioceptive, kinesthetic and tactile senses: the capacity to have keen awareness about the relation of one's own arm to the rest of one's body, and the manner in which taking small steps positions one's own body in relation to another body.

This approach to somatic skill offers a significant step in moving away from the search for a brain area thought to be responsible for skilled movement. It offers a way to step out of our heads and into the context in which we are engaging our bodyminds. By linking skill to the perceptive system and to the capacity to judge, an inherent multilocality for its conceptualization is opened up. If skill in Taijutsu is centrally anchored in the processes of embodied judgements as I suggest, this also highlights that these processes of noticing, similar to all judgements in social life, are distributed across the individual bodies and the contexts in which they come into existence.

Furthermore, what is significant to note is that these judgements occur in an intersubjective space, one that is embodied and sensorial and indeed cannot be subjectively experienced nor understood. This embodied space is also dynamic; not something that can be predicted but something that the body as a process can be cultivated to become engaged with. In Erin Manning's words, the somatic process "is sensed, but not within a consciousness-of that belongs to a subject external to the event" (168). Manning reminds us of the limits of any cohesive "I" being part of a

\footnotetext{
${ }^{12}$ For influential accounts of embodied cognition, see Johnson and Lakoff and Thompson.

${ }^{13}$ In terms of neurological research into skill acquisition, we can note that neurological mappings of brain function through functional MRI suggest that expert brains, for example in the case of drawing skills, are characterized not by an increased activation in given brain regions, but rather by a decrease in the overall brain activation when compared with the novice (see Solso). From this it seems, expertise is equally linked to the absence of neuronal activity as much to any particular presence of neuronal networks themselves.
} 
skilled movement. Manning's phenomenological account itself, however, seems to limit the analysis of somatic movement to the subjective, rather than to the dynamic ways in which the subjective (including the subjectivity of the thinker) becomes immersed in the intersubjective through haptic interaction.

From here, the manner in which people conceptualize the nature of their mindbodies and the manner in which they approach the cultivation of somatic learning can also be opened up. Rather than mechanically repeating patterns that can be performed on command, somatic cultivation, and maybe learning more generally, can be regarded as a process of shared attunement. Such attunement, like the storytelling that Ingold invites us to think about, is always a situationally particular occurrence, an open-ended process of cultivation rather than acquisition of something thoroughly internal. In other words, the focus of skilled engagement becomes first and foremost upon the relationships between any subjects, including absences, rather than on the singular or a material constitution of the subjects themselves. ${ }^{14}$

${ }^{14}$ Acknowledgements: Part of this chapter has been previously published in Semiotics 2009: Semiotics of Time; thanks to the American Semiotic Society for the permission to publish those segments here. Many thanks to the editors of this issue, Ada Jaarsma and Alexis Shotwell for their helpful feedback and for their labor in putting together this special issue. Also thanks to the anonymous reviewers, as well as to the ever insightful semiotician Myrdene Anderson for her endlessly generous and detailed editorial skills over the years. 


\section{Works Cited}

ABRAM, David. Becoming Animal: An Earthly Cosmology. Random House, 2011.

-. The Spell of the Sensuous: Perception and Language in a More-thanHuman World. New York: Vintage, 1999.

ADAMS, Mary-Louise. Artistic Impressions: Figure Skating, Masculinity, and the Limits of Sport. Toronto: University of Toronto Press, 2011.

BARAD, Karen. Meeting the Universe Halfway: Quantum Physics and the Entanglement of Matter and Meaning. Durham: Duke, 2007.

BLACKMAN, Lisa. Immaterial Bodies: Affect, Embodiment, Mediation. London: Sage, 2012.

CANALES, Jimena. A Tenth of a Second: A History. Chicago: Chicago University Press, 2012.

CHEN, Mel Y. Animacies: Biopolitics, Racial Mattering, and Queer Affect. Durham, NC: Duke, 2012.

CSORDAS, Thomas J. "Somatic Modes of Attention." Cultural Anthropology 8, no. 2(1993):135 - 56.

EDELMAN, Gerald M. Second Nature: Brain Science and Human Knowledge. New Haven: Yale University Press, 2007.

FITTS, Paul Morris and Michael I Posner. Human Performance. Belmont, CA: Brooks/Cole, 1967.

FREIRE, Paolo. The Pedagogy of the Oppressed. Translated from the Portuguese by Myra Bergman Ramos. Herder and Herder, 1970.

GEURTS, Kathryn Linn. Culture and the senses: Bodily ways of knowing in an African community. Berkeley, CA: University of California Press, 2002.

GIBSON, James J. The ecological approach to visual perception. Boston: Houghton-Mifflin, 1979.

HAYLES, Katherine N. "Flesh and Metal: Reconfiguring the Mindbody in Virtual Environments." Semiotic Flesh: Information and the Human Body (Short Studies from the Walter Chapin Simpson Center for the Humanities). Ed. Phillip Thurtle and Robert Mitchell. Seattle, WA: Walter Chapin Simpson Center for the Humanities, University of Washington. 2002. $61-68$.

HOWES, David and Constance Classen. Ways of Sensing: Understanding the Senses and the Society. New York: Routledge, 2013. 
INGOLD, Tim. "Stories Against Classification: Transport, Wayfaring and the Integration of Knowledge." Kinship and Beyond: The Genealogical Model Revisited. Ed. Sandra Bamford and James Leach. Oxford: Berghahn Books, 2009. 193- 213.

—. Being Alive: Essays on Movement, Knowledge, and Description. New York: Routledge, 2011.

INGOLD, Tim and Jo Lee VERGUNST (eds.) Ways of Walking: Ethnography and Practice on Foot. Aldershot, England: Ashgate, 2008.

KOHN, Eduardo. How Forests Think: Toward an Anthropology Beyond the Human. Berkeley: University of California Press, 2013.

KORSMEYER, Carolyn. "Delicious, Delightful, Disgusting." The Journal of Aesthetics and Art Criticism 60, no. 3 (2002):217 - 225.

KURIYAMA, Shigehisa. The Expressiveness of the Body and the Divergence of Greek and Western Medicine. New York, NY: Zone Books, 2002.

LAKOFF, George and Mark Johnson. Philosophy in Flesh: The Embodied Mind and its Challenge to Western Thought. New York: Basic Books, 1999.

MANNING, Erin. "Wondering the World Directly - or, How Movement Outruns the Subject." Body and Society, 20, no. 3 \& 4 (2014):162 -188 .

MASSUMI, Brian. Parables of the Virtual: Movement, Affect, Sensation. Duke University Press, 2003.

MERLIN, Donald. A Mind so Rare: The Evolution of Human Consciousness. New York: W. W. Norton \& Company, 2002.

MERRELL, Floyd. Sensing Corporeally: Toward a Posthuman Understanding. Toronto: University of Toronto Press, 2003.

MULLIS, Eric C. "Martial Somaesthetics." The Journal of Aesthetic Education 47, no. 3 (2013): 96-115.

NOË, Alva. Out of Our Heads: Why You Are Not Your Brain, and Other Lessons from the Biology of Consciousness. New York: Hill and Wang, 2009.

PARADIS, Elise. "Boxers, Briefs or Bras? Bodies, Gender and Change in the Boxing Gym". Body Society, 18 no. 2, 2012: 82-109.

PEIRCE, Charles Sanders. "The Principles of Phenomenology." Philosophical Writings of Peirce. Ed. Justus Buchler, New York: Dover Publications Inc., 1955. 74- 97 
PETTINEN, Katja. "From Habits of Doing to Habits of Feeling: Skill Acquisition in Taijutsu Practice". The Encultured Brain: An Introduction to Neuroantropology. Ed. Daniel Lende \& Graig Downey. Cambridge, MA: The MIT press. 2012, 195 - 212.

ROSE, Nikolas. Neuro: The New Brain Sciences and the Management of the Mind. Princeton, NJ: Princeton University Press, 2013.

SALTHE, Stanley. Development and Evolution: Complexity and Change in Biology. Cambridge, MA: MIT Press, 1993.

SHARP, Hasana. Spinoza and the Politics of Renaturalization. Chicago: University of Chicago press, 2011.

SHEETS-JOHNSTONE, Maxine. The Primacy of Movement: Expanded second edition. Philadelphia: John Benjamins Publishing Company, 2011.

SEDWICK, Eve Kosofsky. Touching Feeling: Affect, Pedagogy, Performativity. Durham, NC: Duke University Press, 2003.

SOLSO, Robert L. "Brain Activities in a Skilled versus a Novice Artist: An fMRI Study", Leonardo 34, no. 1 (2001): 31- 34.

SUZUKI, Tadashi. Ekkyô suru Chikara, trans. From the Japanese by J. Thomas Rimer as The Way of Acting: The Theatre Writings of Tadashi Suzuki. New York: Theatre Communications Group, Inc., 1986.

THOMPSON, Evan. Mind in Life: Biology, Phenomenology, and the Science of Mind. Cambridge: Harvard University Press, 2007.

TOMASELLO, Michael. Origins of Human Communication. Cambridge, MA: MIT Press, 2008.

VAN CAMPEN, Cretien. The Hidden Sense: Synesthesia in Art and Science. Cambridge, MA: MIT Press, 2009.

VARELA, Francisco J., Evan THOMPSON, and Eleanor ROSCH. The Embodied Mind: Cognitive Science and Human Experience. Cambridge, MA: MIT press, 1991. 